\title{
Effect of surgery and efferent duct ligation on testicular blood flow and testicular steroidogenesis in the rat
}

\author{
J. M. Wang, C. H. Gu, L. Tao and X. L. Wu \\ Department of Pharmacology, Nanjing Institute of Materia Medica, Nanjing, \\ People's Republic of China
}

\begin{abstract}
Summary. A moderate reduction in testicular blood flow was observed in both testes $24 \mathrm{~h}$ after unilateral efferent duct ligation without any corresponding change in testosterone secretion as indicated in the peripheral blood, in testicular venous blood, or in testicular tissue fluid. At 21 days a pronounced unilateral decrease in blood flow was associated with the extensive degeneration of tubules in the testis on the ligated side. These changes were also associated with decreased testosterone secretion by the testis on the ligated side, although Leydig cell function was not abolished since testosterone in the tissue increased rather than decreased. It is therefore concluded that testicular blood flow may play an important role in the changes of testosterone secretion that follow unilateral efferent duct ligation.
\end{abstract}

\section{Introduction}

The profound tubular changes subsequent to ligation of the efferent ducts of the testis are well known (White, 1933; Smith, 1962), but the changes in Leydig cell function remain unclear. Previous studies of the effect of efferent duct ligation on the endocrinological function of the testis were done without much consideration of the accompanying changes in testicular blood flow which certainly complicate the situation and affect the local output of testosterone (Collins, Collins, McNeilly \& Tsang, 1978; Collins \& Tsang, 1979; Risbridger, Kerr, Peake \& de Kretser, 1981). The aim of this experiment was to elucidate further the relationship between testicular blood flow and testosterone production after unilateral ligation of the efferent ducts in rats.

\section{Materials and Methods}

Animals. Male Wistar rats weighing $324 \pm 5.5$ (s.e.m.) g were housed under conditions of controlled temperature $\left(15-20^{\circ} \mathrm{C}\right)$ with at least $12 \mathrm{~h} \mathrm{light}$ per day and free access to food and water. They were allocated at random into five groups: Group 1 (controls), 10 rats without any surgical intervention before the measurement of blood flow and blood sampling; Group 2 (sham operation), 8 rats in which a sham operation of abdominal incision and exteriorization of the left testis was done $24 \mathrm{~h}$ previously; Groups 3, 4 and 5, containing 8,9 and 12 rats respectively, in which the efferent ducts were ligated $24 \mathrm{~h}, 7$ days and 21 days earlier, respectively.

Testicular blood flow and hormone secretion. Testicular blood flow was measured by a microsphere technique (Damber \& Janson, 1977; Wang, Galil \& Setchell, 1983; Wang, Gu, Qian \& Jing, 1984). In rats anaesthetized with pentobarbitone sodium (Sagatal: May \& Baker, Essex, U.K.; 50 $\mathrm{mg} / \mathrm{kg}$ i.p.) one polyvinyl catheter $(0.8 \mathrm{~mm}$ o.d., $0.5 \mathrm{~mm}$ i.d.; Dural Plastics, New South Wales, Australia) was introduced into the left carotid artery for injection of microspheres, one into the left femoral artery for collection of reference blood sample and one into the tail artery for monitoring of blood pressure. The microspheres labelled with ${ }^{57} \mathrm{Co}$ were purchased from New England Nuclear, Boston, U.S.A. The blood flows to the whole epididymides of fboth $_{1}$ sides $_{\text {and }}$ both kidneys 2 were ${ }_{1: 58: 04 \mathrm{PM}}$ 
measured simultaneously in each experiment. The details of the microsphere technique, the methods for collection of testicular venous blood and testicular tissue fluid were as described previously (Wang et al., 1984). For some animals in each group, both testes were fixed by perfusion with saline $(0.154 \mathrm{M}-\mathrm{NaCl})$ followed by Bouin's fluid into the testicular artery and then embedded in paraffin wax and sections made for histological study.

Radioimmunoassay. Testosterone concentrations in various samples were determined by radioimmunoassay. The testosterone antiserum was obtained from the Research Laboratory of Endocrinology, Second Shanghai Medical College (1978) which was raised in a rabbit against testosterone-3-BSA. The percentage cross-reaction to $5 \alpha$-dihydrotestosterone was $50 \%$. However, Sephadex-LH-20 column chromatography was omitted because rat blood has been shown to contain a negligible amount of $5 \alpha$-dihydrotestosterone (Falvo \& Nalbandov, 1974). The testosterone assay had an intra-assay coefficient of variation of $5.6 \%$ and inter-assay coefficient of variation of $7 \cdot 2 \%$. The sensitivity of the standard curve was $10 \mathrm{pg}$.

Testosterone production was calculated by multiplying the difference in testosterone concentrations between testicular venous and arterial plasma by plasma flow which was obtained by multiplying blood flow by ( 1 - haematocrit value). The haematocrit value of the rats was presumed to be $45 \%$ (see Mather \& Rushmer, 1979; Wang et al., 1984).

Blood pressure was measured by a mercury manometer connected to the indwelling catheter in the tail artery before and during the injection of microspheres.

Statistical tests. The data were expressed as mean \pm s.e.m. and assessed by one-way analysis of variance as well as Student's $t$ test for comparison of mean values between the control and the treated groups.

\section{Results}

Organ weights

Testicular weight was markedly increased in Group 3 rats compared with the control values $(P<0.01)$. The effect was more pronounced in Group 4, and in Group 5 the ligated testes showed a drastic reduction in weight in comparison with the contralateral side or with the control value $(P<0.01$; Text-fig. 1).

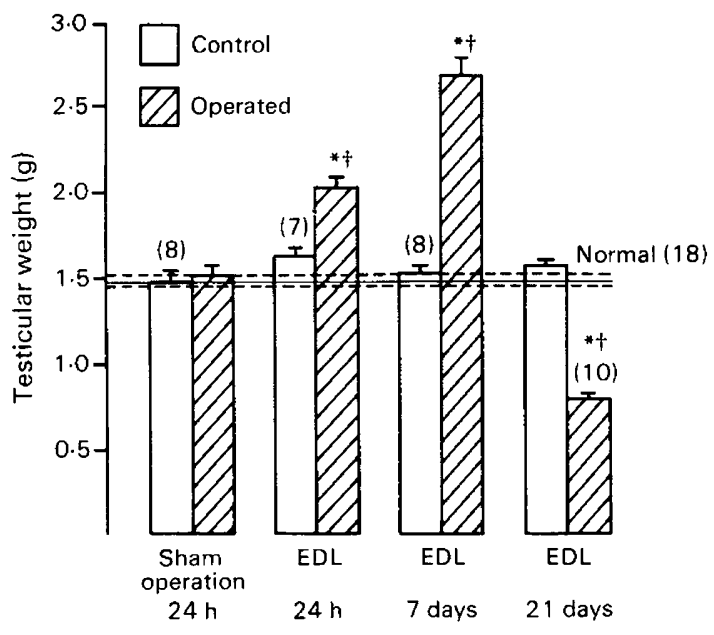

Text-fig. 1. Effect of unilateral ligation of the efferent duct of rats on testicular weight. Values are mean \pm s.e.m. for the numbers of rats indicated. ${ }^{*} P<0.01$ compared with values for control side; $\uparrow P<0.01$ compared with value for normal rats (Group 1). 


\section{Blood flow}

The testicular blood flow on the ligated side as well as on the contralateral untreated side was reduced in rats of Groups 2 and 3 compared with that in Group 1 rats (Table 1). The blood flow to the ligated testes in Group 3 was reduced more markedly than that of the contralateral testes. Thereafter, the blood flow to the unoperated testis recovered to a normal level in Groups 4 and 5 while the values to the ligated testes remained low (Table 1). The value of the blood flow in terms of $\mu 1 / \mathrm{min} / \mathrm{g}$ to the ligated testis in Group 4 rats was reduced mainly because of the marked increase in testicular weight in this group, the value per testis having reached the normal level at this time (see Table 2).

Table 1. Effect of unilateral ligation of the efferent ducts (EDL, left side) of rats on organ blood flows

\begin{tabular}{|c|c|c|c|c|c|c|c|}
\hline \multirow[b]{2}{*}{ Group } & \multirow{2}{*}{$\begin{array}{l}\text { No. of } \\
\text { rats }\end{array}$} & \multicolumn{2}{|c|}{ Testis $(\mu 1 / \mathrm{min} / \mathrm{g})$} & \multicolumn{2}{|c|}{$\begin{array}{r}\text { Epididymis } \\
(\mu \mathrm{l} / \mathrm{min} / \mathrm{g})\end{array}$} & \multicolumn{2}{|c|}{ Kidney $(\mu \mathrm{l} / \mathrm{min} / \mathrm{g})$} \\
\hline & & Left & Right & Left & Right & Left & Right \\
\hline $\begin{array}{l}1 \text { Intact (controls) } \\
2 \text { Sham operation, } 24 \mathrm{~h} \\
3 \text { EDL, } 24 \mathrm{~h} \\
4 \text { EDL, } 7 \text { days } \\
5 \text { EDL, } 21 \text { days }\end{array}$ & $\begin{array}{r}9 \\
8 \\
7 \\
8 \\
10\end{array}$ & $\begin{array}{l}431 \pm 54 \\
331 \pm 45^{\mathrm{c}} \\
219 \pm 27^{\mathrm{b}, \mathrm{d}} \\
253 \pm 41^{\mathrm{b}, \mathrm{d}} \\
290 \pm 42^{\mathrm{a}, \mathrm{d}}\end{array}$ & $\begin{array}{l}493 \pm 43 \\
353 \pm 27^{\circ} \\
368 \pm 42^{\circ} \\
435 \pm 52 \\
445 \pm 57\end{array}$ & $\begin{array}{l}161 \pm 34 \\
144 \pm 23 \\
184 \pm 25 \\
215 \pm 36 \\
171 \pm 23\end{array}$ & $\begin{array}{l}160 \pm 12 \\
190 \pm 54 \\
142 \pm 23 \\
186 \pm 29 \\
199 \pm 29\end{array}$ & $\begin{array}{l}5276 \pm 637 \\
6254 \pm 985 \\
6074 \pm 496 \\
5555 \pm 597 \\
6638 \pm 668\end{array}$ & $\begin{array}{l}5971 \pm 1068 \\
5867 \pm 824 \\
4961 \pm 1034 \\
5171 \pm 629 \\
6054 \pm 661\end{array}$ \\
\hline
\end{tabular}

a $P<0.05 ;{ }^{b} P<0.01$, compared to the right side.

${ }^{c} P<0.05 ;{ }^{d} P<0.01$, compared to Group 1 .

Table 2. Effect of unilateral efferent duct ligation of rats on testosterone secretion (mean \pm s.e.m.)

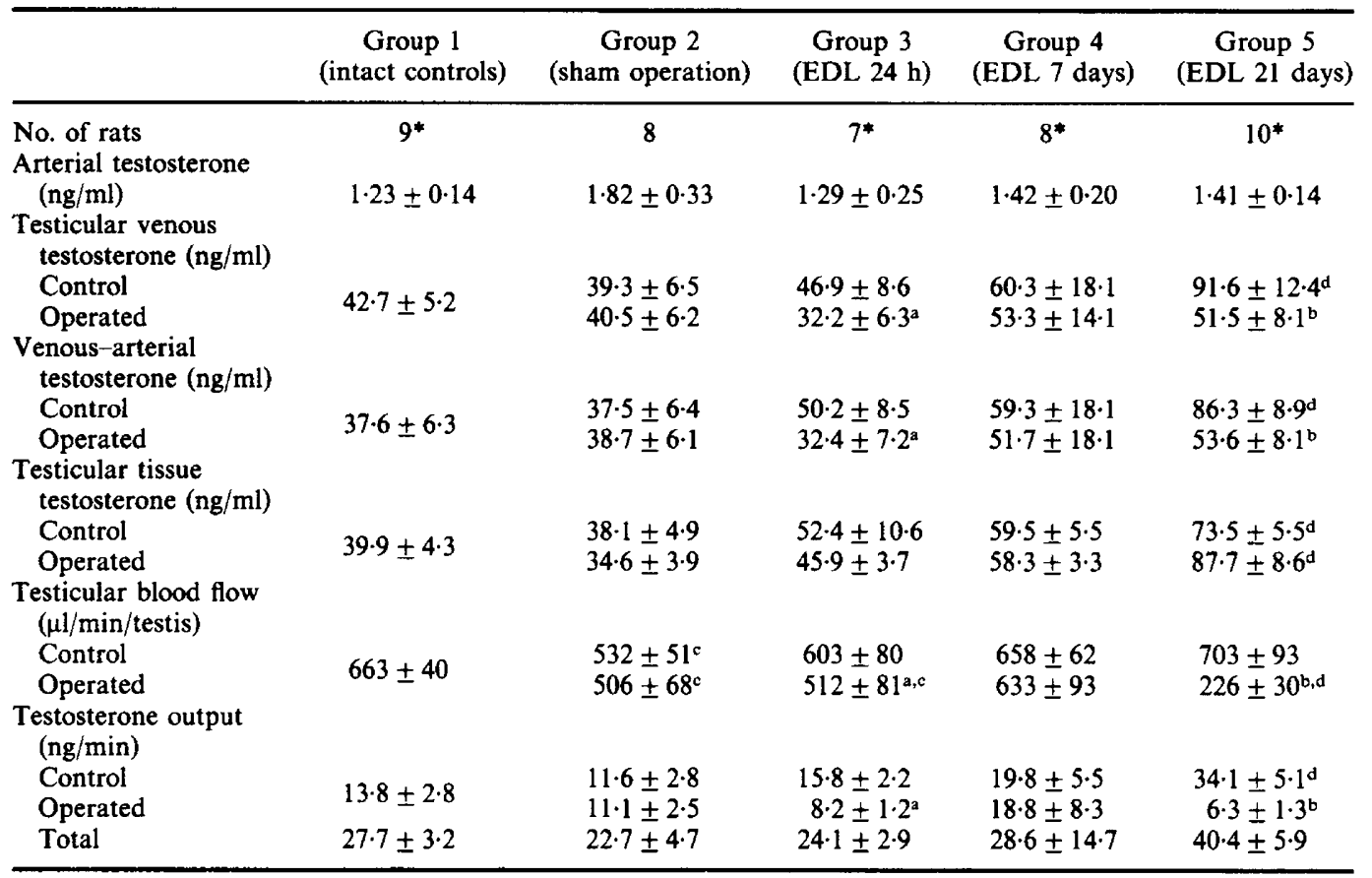

${ }^{\text {a }} P<0.05 ;{ }^{b} P<0.01$, compared with values for control side.

${ }^{c} P<0.05 ;{ }^{d} P<0.01$, compared with values for Group 1 .

* Some samples were lost due to difficulties experienced in sample collection. 
In spite of the reduction of testicular blood flow on both sides after sham operation or after efferent duct ligation blood flows to the epididymides and kidneys remained unchanged (Table 1). Blood pressure was determined during measurement of blood flow. The mean value for each group was $105 \pm 6.5 \mathrm{mmHg}$ in the operated animals $(24 \mathrm{~h}$ after sham operation and efferent duct ligation) compared with $101 \pm 4.5 \mathrm{mmHg}$ in the control unoperated rats. The reduction of testicular blood flow in the early post-operative period therefore appears to be due to local rather than systemic factors.

\section{Steroidogenesis}

The concentrations of testosterone in peripheral arterial blood were virtually identical in the different groups (Table 2). Neither was there any significant change in testicular venous and testicular tissue testosterone concentrations after sham operation or short-term efferent duct ligation. The marked increase of testicular weight in Groups 3 and 4 occurred with little change in the hormone concentration in testicular venous blood and testicular fluid in the same testis compared with control values. In Group 5 rats blood flow per testis was reduced nearly 3 -fold in comparison with the control or contralateral values, but testicular tissue testosterone concentration was not reduced (Table 2). However, the drastic reduction in testicular blood flow in Group 5 rats resulted in a very much reduced output of testosterone in spite of the virtually unchanged or somewhat increased venous-arterial difference for testosterone in such circumstances. In addition, a compensatory increase in testosterone output by the contralateral control testes in Group 5 rats was observed. Moreover, despite the fact that the arterial testosterone concentration was constant, there was a tendency for testosterone concentrations in testicular venous and testicular tissue sample to increase on both sides in rats in Group 5.

\section{Morphology}

The blockade of outflow caused by efferent duct ligation resulted in marked distension of the lumen of the seminiferous tubules as well as the interstitial space within $24 \mathrm{~h}$ (Group 3 ) and this distension persisted for 7 days (Group 4). Pathological changes in the seminiferous epithelium were visible in the testes of Group 4 rats shown by a marked reduction in the numbers of mature spermatozoa, occurrence of desquamation of epithelial cells and vacuolation of the nuclei of spermatids. However, in Group 5 rats the majority of the tubules showed extensive atrophy in which only a few spermatogonia and Sertoli cells and some reticular structures were visible. In contrast to this, the Leydig cells were apparently normal in appearance (P1. 1, Figs 1-4). Counts were made of the Ley-

\section{PLATE 1}

Photomicrographs of the control unoperated testis and testes after different periods of efferent duct ligation (EDL).

Fig. 1. Control testis showing normal structure of germinal epithelium in which spermatogonia, primary spermatocytes, spermatids and mature spermatozoa are seen. H \& E, $\times 583$.

Fig. 2. Testicular tissue at $24 \mathrm{~h}$ after EDL illustrating marked distension of the lumen and enlargement of interstitial spaces, while the seminiferous epithelium is apparently normal. $\mathrm{H} \& \mathrm{E}, \times 583$.

Fig. 3. Testicular tissue at 7 days after EDL in which besides distension of lumen and interstitial spaces, decrease in the numbers of mature spermatozoa, desquamation of the epithelial cells and vacuolation of spermatids are visible. H \& E, $\times 583$.

Fig. 4. Testicular tissue at 21 days after EDL showing extensive atrophy of tubules in which only spermatogonia and Sertoli cells are seen with the formation of reticular structures. The Leydig cells are apparently normal. H \& E, × 583. 
PLATE 1
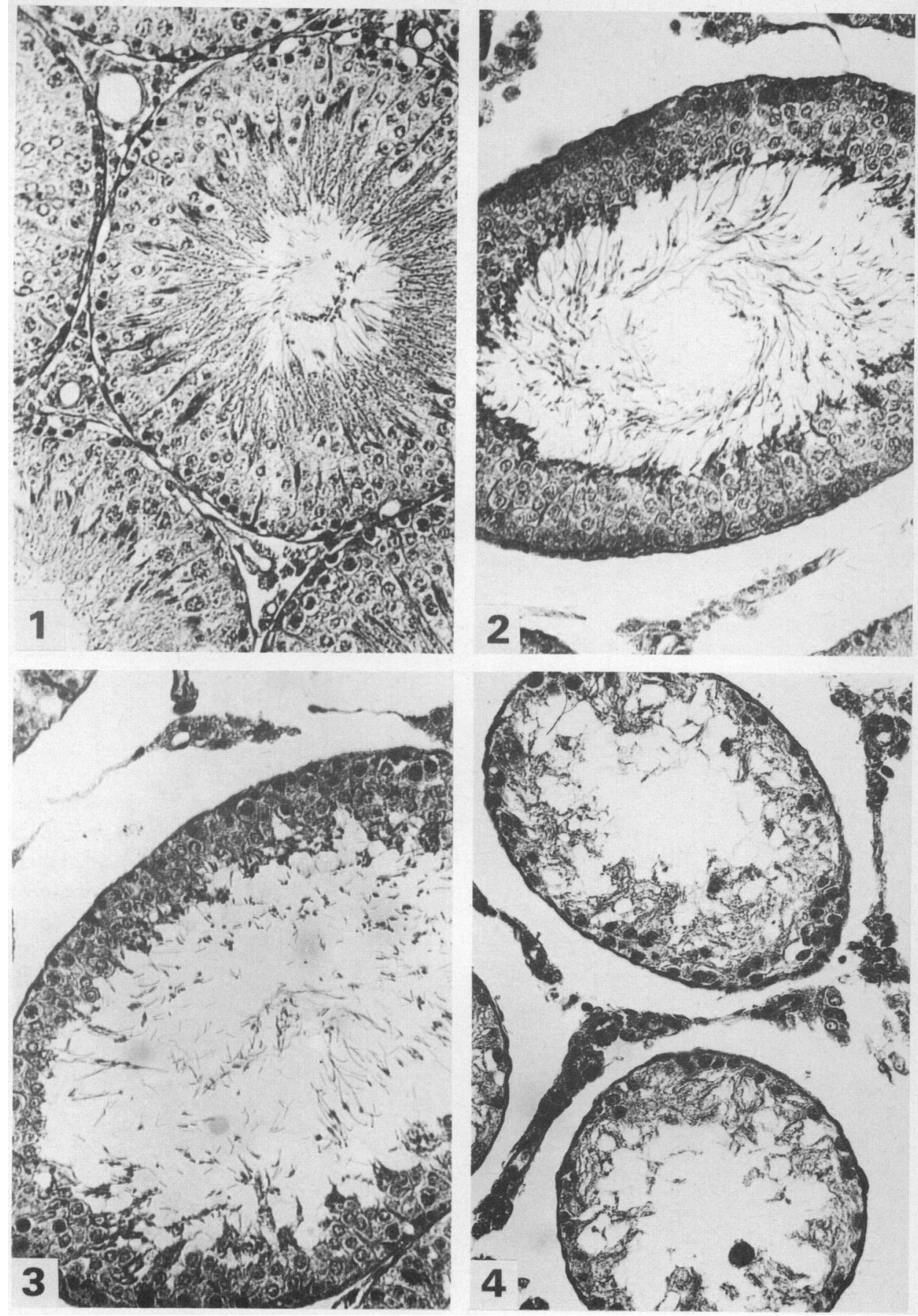
dig cells present in the area delimited by joining the centres of 4 adjacent transversely sectioned tubules: 10 such areas were counted in the ligated testis and the contralateral control testis of each rat in Group 5. The counts were $21.5 \pm 1.56$ for the ligated testis and $23.10 \pm 2.50$ for the control testis $(P>0.05)$, indicating that there was no change in the number of the Leydig cells at 21 days after efferent duct ligation.

\section{Discussion}

The results of this study indicate that the change of testicular blood flow after efferent duct ligation seems to be the primary factor which accounts for the sequence of effects on the testicular steroidogenesis. Damber \& Janson (1978a) found a positive correlation between testicular blood flow and outflow of testosterone in the spermatic vein in vivo, indicating that factors which influence the tonus of the blood vessels of the testis may indirectly affect the synthesis and/or secretion of testosterone. In our experiment a similar correlation also existed in the ligated testes at $24 \mathrm{~h}$ after unilateral efferent duct ligation as reduction of testicular blood flow was accompanied by a corresponding fall in testicular venous testosterone concentration and the venous-arterial difference in testosterone concentration consequently (Table 2).

The early reduction of testicular blood flow $24 \mathrm{~h}$ after unilateral efferent duct ligation requires further consideration. Since it occurs not only in the ligated testis but also in the contralateral testis and in sham-operated animals, it is obvious that such a response is caused by surgical intervention. Owing to the fact that vasoconstriction occurs at a time when blood pressure and blood flow to other organs remains constant, it appears that the vascular response of testes to surgical stress involves some specific local mechanism. A similar reduction of testicular blood flow was also observed in rats after laparotomy and exposure of the right spermatic vein by Damber \& Janson (1978a) who attributed it to a reduction in systemic blood pressure.

Damber \& Janson (1978b) in an acute experiment on rats found that perfusion of catecholamines caused a fall in concentration of testosterone without changes in the absolute values of testicular blood flow which was assumed to be responsible for the decrease in testosterone secretion observed in male rats exposed to stress. In other words, a direct effect was exerted on the Leydig cells in such circumstances. There was no evidence in our experiment to show any depressive effect on the Leydig cell function in the early post-operative period, as the concentration of testosterone in testicular tissue fluid did not show any alteration when blood flow was reduced. Therefore, it seems that a minor surgical operation like laparotomy and unilateral efferent duct ligation induces a reduction of blood flow to both testes without affecting testicular steroidogenesis in the early postoperative period. It is thus reasonable to suppose that the acute depressive effect on testicular steroidogenesis observed in surgical patients (Carstensen, Amer, Amer \& Wide, 1973a; Carstensen, Amer, Wide \& Amer, 1973b) may involve a vascular adaptation which subsequently leads to a lowering of testosterone concentration in peripheral blood.

The concurrent increase of testosterone concentration in testicular tissue fluid of the ligated side at 21 days after efferent duct ligation may be accounted for by the local accumulation of steroid due to reduction of blood flow subsequent to severe tubular damage and testicular atrophy.

Risbridger et al. (1981) found an enhanced testosterone response to gonadotrophin stimulation in vitro in the unilaterally ligated testes but not in the unligated contralateral testes of the same animals. The authors claimed that the modifications of Leydig cell function after efferent duct ligation are mainly due to local changes within the testes, providing further evidence for an intratesticular control of Leydig cell function. However, since there was a concurrent tendency of increment in testosterone concentration both in testicular venous blood and testicular tissue fluid of the contralateral control testis at 21 days after unilateral efferent duct ligation and Main \& Setchell (1980) found a suggestive rise in serum $\mathbf{L H}$ in such circumstances, it seems that the gonadotrophic system rather than a local mechanism is involved. 
This investigation partly received financial support from the Special Programme of Research in Human Reproduction, World Health Organization, Geneva. We thank Qian Zhong Ming for his participation in the pilot experiments; Dr Zhang Jien Ming for help with the histology; and Dr R. B. Heap and Mr M. S. Laurie for critically reading the manuscript.

\section{References}

Carstensen, H., Amer, B., Amer, I. \& Wide, L. (1973a) The postoperative decrease of plasma testosterone in man, after major surgery, in relation to plasma FSH and LH. J. Steroid Biochem. 4, 45-55.

Carstensen, H., Amer, I., Wide, L. \& Amer, B. (1973b) Plasma testosterone, LH and FSH during the first 24 hours after surgical operations. J. Steroid Biochem. 4, 605-611.

Collins, P.M. \& Tsang, W.N. (1979) An assessment of the function of the seminiferous tubules and interstitium of the rat testis following ligation of the vasa efferentia. Biol. Reprod. 20, 671-680.

Collins, P.M., Collins, W.P., McNeilly, A.S. \& Tsang, W.N. (1978) Plasma FSH, LH and testosterone levels in the male rat during degeneration of the germinal epithelium caused by severe heat treatment or ligation of the vasa efferentia. J. Reprod. Fert. 54, 285-291.

Damber, J.E. \& Janson, P.O. (1977) Methodological aspects of testicular blood flow measurement in rats. Acta physiol. scand. 101, 278-285.

Damber, J.E. \& Janson, P.O. (1978a) Testicular blood flow and testosterone concentrations in spermatic venous blood of anaesthetized rats. J. Reprod. Fert. 52, 265-269.

Damber, J.E. \& Janson, P.O. (1978b) The effects of LH, adrenaline and noradrenaline on testicular blood flow and plasma testosterone concentrations in anaesthetized rats. Acta endocr., Copenh. 88, 390-396.

Falvo, R.E. \& Nalbandov, A.V. (1974) Radioimmunoassay of peripheral testosterone in males from eight species using a specific antibody without chromatography. Endocrinology 95, 1466-1468.

Main, S.J. \& Setchell, B.P. (1980) Responsiveness of the pituitary gland to androgens and of the testis to gonadotrophins following damage to spermatogenesis in rats. J. Endocr. 87, 445-454.

Mather, E.C. \& Rushmer, R.A. (1979) Physiological parameters of some species used in reproduction research. In Animal Models for Research in Contraception and Fertility, pp. 561-576, Ed. N. J. Alexander. Harper \& Row, New York.

Research Laboratory of Endocrinology, Second Shanghai Medical College (1978) Radioimmunoassay of plasma testosterone. Zhonghua Yixue Jianyan Zazhi (Chinese Journal of Medical Laboratory Technology) 1, 19-24.

Risbridger, G.P., Kerr, J.B., Peake, R.A. \& de Kretser, D.M. (1981) An assessment of Leydig cell function after bilateral or unilateral efferent duct ligation: further evidence for local control of Leydig cell function. Endocrinology 109, 1234-1241.

Smith, G. (1962) The effects of ligation of vasa efferentia and vasectomy on testicular function in the adult rat. J. Endocr. 23, 385-399.

Wang, J., Galil, K.A.A. \& Setchell, B.P. (1983) Changes in testicular blood flow and testosterone production during aspermatogenesis following $\mathrm{X}$-irradiation. $J$. Endocr. 98, 35-46.

Wang, J.M., Gu, C.H., Qian, Z.M. \& Jing, G.W. (1984) Effect of gossypol on testicular blood flow and testosterone production in rats. J. Reprod. Fert. 71, 127-133.

White, W.E. (1933) The duration of fertility and the histological changes in the reproductive organs after ligation of the vasa efferentia in the rat. Proc. $R$. Soc. $B$ 113, 544-550. 